\title{
Promoter-proximal pausing of RNA polymerase II defines a general rate- limiting step after transcription initiation
}

\author{
Anton Krumm, ${ }^{1,3}$ Laurie B. Hickey, ${ }^{1}$ and Mark Groudine ${ }^{1,2}$ \\ ${ }^{1}$ Fred Hutchinson Cancer Center, Seattle, Washington 98104 USA; ${ }^{2}$ Department of Radiation Oncology, University \\ of Washington School of Medicine, Seattle, Washington 98195 USA
}

\begin{abstract}
We have shown previously that the majority of RNA polymerase II complexes initiated at the c-myc gene are paused in the promoter-proximal region, similar to observations in the Drosophila hsp 70 gene. Our analyses define the TATA box or initiator sequences in the c-myc gene as necessary components for the establishment of paused RNA polymerase II. Deletion of upstream sequences or even the TATA box does not influence significantly the degree of transcriptional initiation or pausing. Deletion of both the TATA box and sequences at the transcription initiation site, however, abolishes transcriptional pausing of transcription complexes but still allows synthesis of full-length RNA. Further analyses with synthetic promoter constructs reveal that the simple combination of upstream activator with TATA consensus sequences or initiator sequences act synergistically to recruit high levels of RNA polymerase II complexes. Only a minor fraction of these complexes escapes into regions further downstream. Several different trans-activation domains fused to GAL4-DNA-binding domains, including strong activators such as VP16, do not eliminate promoter-proximal pausing of RNA polymerase. Thus, we conclude that pausing of RNA polymerase II is a common phenomenon in eukaryotic transcription and does not require complex promoter structures. Further analyses reveal that enhancers have a modest influence on transcription initiation and on release of transcription complexes out of the pause site but may function primarily to increase the elongation competence of transcription complexes.
\end{abstract}

[Key Words: C-myc gene; promoter-proximal pausing; RNA polymerase II; transcription initiation; elongation; enhancer]

Received November 30, 1994; revised version accepted January 26, 1995.

The level of c-myc RNA is regulated largely through a mechanism that operates after transcription initiation. This conclusion is based on the observation that steadystate c-myc RNA levels decline significantly as cells differentiate, whereas transcriptional initiation, as measured in nuclear run-on assays, remains unchanged (Bentley and Groudine 1986; Eick and Bornkamm 1986; Nepveu and Marcu 1986; for review, see Spencer and Groudine 1990; Krumm et al. 1993).

Recent in vivo assays have demonstrated paused RNA polymerase II complexes at promoter-proximal regions of the $c-m y c$ gene. For example, in vivo footprinting with $\mathrm{KMnO}_{4}$ as a reagent to detect single-stranded DNA residues within transcription bubbles revealed hyper-reactive sites around position +30 . These results suggested that RNA polymerases pause in the promoter-proximal region around +30 . Nuclear run-on experiments with short probes confirmed that the majority of RNA polymerases is located within the first $169 \mathrm{bp}$ (Krumm et al. 1992). In another study, nuclear run-on experiments with oligonucleotide probes as short as $50 \mathrm{bp}$ also indi-

\footnotetext{
${ }^{3}$ Corresponding author.
}

cated that the highest level of RNA polymerase II is within the promoter-proximal region between +1 and +50 (Strobl and Eick 1992). Further experiments demonstrated that sequences $5^{\prime}$ of +47 were sufficient to confer promoter-proximal pausing (Krumm et al. 1992).

Promoter-proximal pausing of RNA polymerase II has also been observed in the $h s p 70$ and other genes in Drosophila (Rougvie and Lis 1988; O'Brien and Lis 1991; for review, see Lis and Wu 1993) and may be responsible for polarity of transcription observed in other genes such as the human immunodeficiency virus-long terminal repeat (HIV-LTR) (Kao et al. 1987; Laspia et al. 1989; for review, see Cullen 1993). Similar to the c-myc gene, transcription initiation in the Drosophila hsp 70 gene appears to be unchanged in induced (heat-shocked) and noninduced (nonheat-shocked) cells. In both c-myc and hsp 70, promoter-proximal pausing is detected in nuclear run-on assays by the high salt- or Sarkosyl-mediated release of RNA polymerase complexes paused at or immediately downstream of the transcription initiation site. Results of nuclear run-on assays with the $h s p 70$ gene correlate with those of UV cross-linking assays where high amounts of RNA polymerase II were cross-linked to 
promoter-proximal DNA, and only little was detected on downstream sequences (Rougvie and Lis 1988; O'Brien and Lis 1991). In addition, in vivo footprinting with $\mathrm{KMnO}_{4}$ and sizing of short RNAs generated in nuclear run-ons further confirmed that RNA polymerase II pauses at promoter-proximal regions /Giardiana et al. 1992; Rasmussen and Lis 1993).

Pausing of RNA polymerase II has been found to be a target for regulation of gene expression in prokaryotes. For example, promoter-proximal pausing is an important component of the antitermination mechanism at the $\lambda$ $\mathrm{pR}^{\prime}$ promoter, where RNA polymerase pauses 16 bases downstream of the initiation site and requires the $Q$ protein to escape the pause site and resume elongation (for review, see Greenblatt et al. 1993; Roberts 1993). The interaction of the transcription complex with the $Q$ protein also results in the suppression of termination signals farther downstream. In addition, the antitermination activity of the $\lambda \mathrm{N}$ protein has been suggested to rely on the suppression of pausing of polymerase at the Rhodependent $\lambda$ terminator (Mason et al. 1992).

Here, we present experiments that delineate the sequences involved in promoter-proximal pausing of RNA polymerase II complexes in mammalian cells. In reconstitution experiments, we show that promoter-proximal pausing occurs to a high level in simple promoter constructs. Both core promoter sequences and upstream activators synergize to recruit high levels of transcription complexes pausing within promoter-proximal regions. The formation of paused RNA polymerase II complexes is supported by different classes of upstream activators. This indicates that pausing of transcription complexes is very common and a major rate-limiting mechanism in gene expression. We also show that enhancers and some upstream activators have only a modest effect on transcription initiation and on the release of transcription complexes out of the promoter-proximal pause site; these elements may increase the amount of full-length RNA through modulation of elongation competence of RNA polymerase II, as suggested previously (Krumm et al. 1993; Madisen and Groudine 1994; Yankulov et al. 19941.

\section{Results}

Promoter-proximal pausing functions in the absence of the c-myc consensus TATA box

Promoter-proximal pausing of RNA polymerase II in the $\mathrm{c}-m y c$ gene is also observed when a human $\mathrm{c}-\mathrm{myc}$ construct is transfected into mouse $\mathrm{L}$ cells (Krumm et al. 1992). In these experiments, high amounts of transcription complexes were detected in promoter-proximal regions, and very few RNA polymerase II complexes were found farther downstream. The experimental strategy to identify sequence elements responsible for the generation of paused RNA polymerase included construction of linker scanner and deletion mutants within the human c-myc P2 promoter. After transfection of these constructs into mouse L cells, polyclonal lines were estab- lished and the extent of promoter-proximal pausing was measured in nuclear run-on assays. In this assay, transcriptionally engaged RNA polymerase II complexes in isolated nuclei continue to elongate nascent RNA for an average of 100 to 200 nucleotides. Similar to observations at the Drosophila hsp70 gene /Rougvie and Lis 1988), RNA polymerase II complexes paused in promoter-proximal regions in the $c-m y c$ gene are released and resume elongation only in the presence of a salt concentration of $150 \mathrm{~mm}$ or Sarkosyl (Krumm et al. 1992). The resultant labeled RNA is hybridized to "cold" probes spanning different regions of the gene. Because no reinitiation occurs under the nuclear run-on conditions used in these experiments, this assay measures the distribution of transcription complexes within a gene at the time of nuclear isolation.

The deletion of sequences upstream of the c-myc P2 promoter did not influence the degree of promoter-proximal pausing in comparison to the wild-type c-myc template (data not shown). Further analysis with mutant constructs revealed that sequences within the core promoter are involved in promoter-proximal pausing of transcription complexes. Single base mutations within the TATA box have been reported to decrease initiation in Xenopus oocyte injection experiments; concomitantly, the relative amount of RNA polymerases reading through termination/pause signals further downstream was increased (Meulia et al. 1993; Yankulov et al. 1994). The complete deletion of the TATA consensus sequence, however, abolished transcriptional activity in these assays (Spencer et al. 1990; Meulia et al. 1993). To test whether this holds true in mammalian cells, we transfected a full-length human c-myc construct containing a deletion of the TATA box of the P2 promoter (Spencer et al. 1990) into mouse L cells. Stably transfected, polyclonal cells containing similar numbers of integrated copies were analyzed in a nuclear run-on assay. Surprisingly, deletion of the TATA consensus sequence $(\triangle \mathrm{P} 1 \Delta \mathrm{P} 2 \mathrm{TATA})$ did not abolish the recruitment of RNA polymerase II complexes. The promoter-proximal signal as detected by probe $\mathrm{B}(+47$ to +169$)$ in the nuclear run-on assay was reduced only twofold compared with the control construct $\Delta \mathrm{Pl}$ (Fig. 1A). The nuclear run-on pattern of the $\triangle \mathrm{P} 1 \Delta \mathrm{P} 2 \mathrm{TATA}$ construct is very similar to the pattern observed at the wild-type P2 promoter $(\Delta \mathrm{P} 1$; Fig. 1A). Transcriptional activity is very high in promoter-proximal regions, as detected by probe $\mathrm{B}$, whereas a very small amount of transcription complexes is detected farther downstream, with probes $\mathrm{C}$ $(+170$ to +349$)$, D $(+349$ to +548$)$, and $\mathrm{E}(+775$ to +911). The high signal observed in the absence of a TATA box was sensitive to low $\alpha$-amanitin $(2 \mu \mathrm{g} / \mathrm{ml})$ concentrations (data not shown). Thus, the promoterproximal signal at the TATA-less c-myc promoter is attributable to RNA polymerase II. These results indicate that even in the absence of the TATA consensus sequence, the c-myc promoter can initiate transcription efficiently. These initiated transcription complexes, however, are as inefficient in elongation as at the wildtype $\mathrm{P} 2$ promoter. Thus, the c-myc TATA consensus se- 

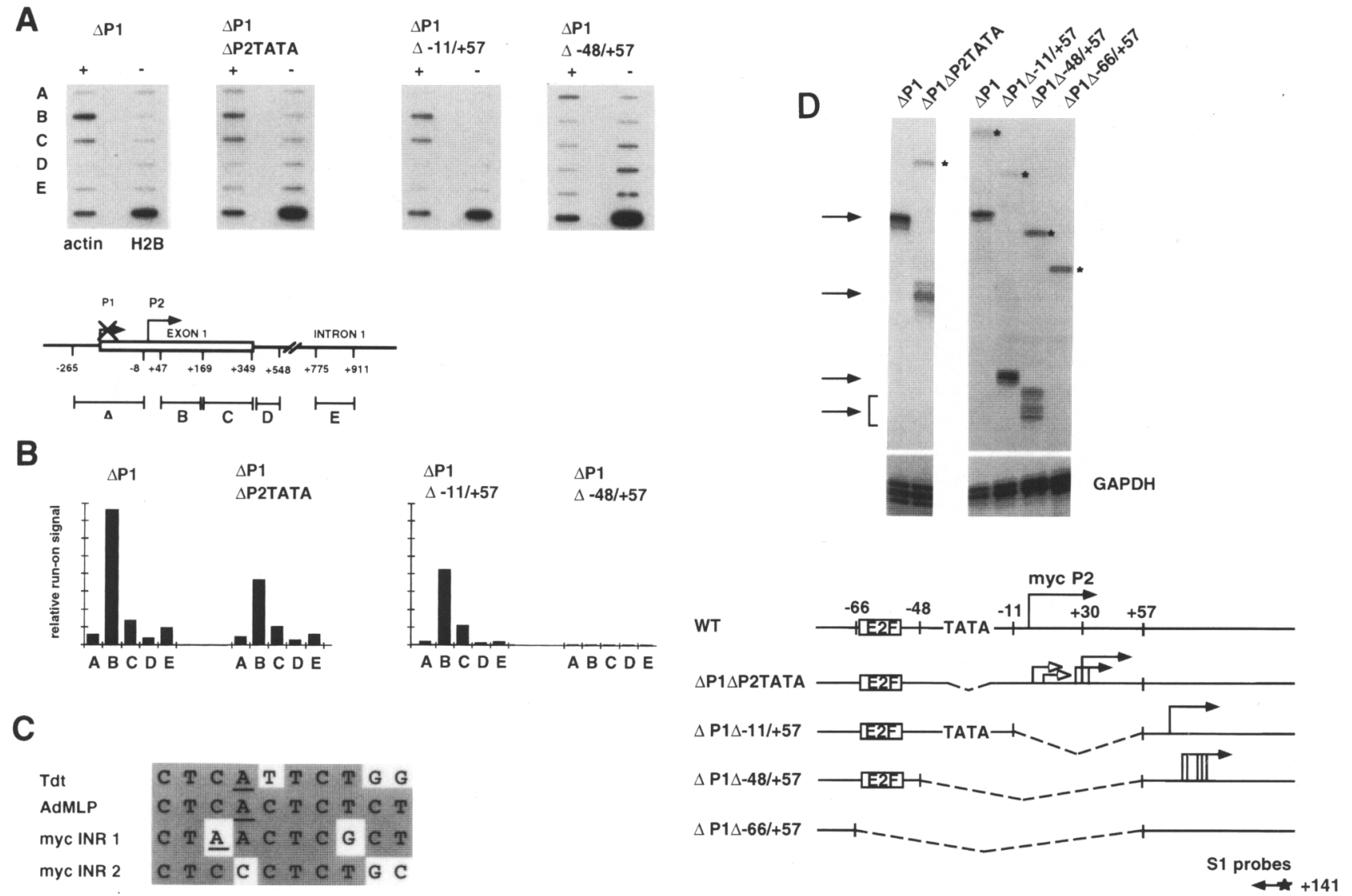

Figure 1. The TATA consensus sequence or sequences at the initiation site of the c-myc promoter are necessary for the formation of paused RNA polymerase. (A) Mouse fibroblasts (L cells), stably transfected with different c-myc constructs containing a wild-type P2 promoter $(\Delta \mathrm{P} 1)$, a deletion of the TATA sequence $(\Delta \mathrm{P} 1 \Delta \mathrm{P} 2 \mathrm{TATA})$, or the initiation region $(\Delta \mathrm{P} 1 \Delta-11 /+57)$ or both the TATA box and the initiation site $(\Delta \mathrm{P} 1 \Delta-48 /+57)$, were analyzed in nuclear run-on assays. Transfected cells were pooled and nuclei were isolated. Nuclear run-on assays were performed in the presence of radioactively labeled UTP, and nascent RNA was isolated and hybridized to single-stranded probes A-E to detect c-myc sense $(+\mid$ and antisense $|-|$ transcription. The structure of the c-myc gene and the position of probes are shown below. $\Delta \mathrm{P} 1$ refers to the deletion of a 30-bp sequence at the P1 promoter located upstream of the P2 promoter (Spencer et al. 1990). The presence of either a TATA box or the initiation region, or both, is required to generate a high level of transcription complexes paused in the promoter-proximal region (probe B). However, only little signal is detected with probes $\mathrm{C}, \mathrm{D}$, and $\mathrm{E}$, indicating that only a small fraction of initiated transcription complexes transcribes regions further downstream. Probes detecting transcription of the actin or the H2B gene were used as internal controls. $(B)$ Quantitation of nuclear run-on signals. The amount of radioactivity bound to each probe was determined using a PhosphorImager system, corrected for the uridine-content of each probe, and normalized to the signals obtained with the actin probe and to the number of integrated copies determined by Southern analyses (not shown). (C) Similarity of sequences at the c-myc initiation site to initiator sequences in the adenovirus major late promoter (AdMLP) and the terminal deoxynucleotidyl transferase gene (Tdt). The sites of transcription initiation are underlined. The c-myc Inr2 sequence is shown in an inversed orientation beginning at position +39 to +31 of the noncoding strand. $(D)$ Nuclease $S 1$ analysis of steady-state c-myc RNA of transfected mouse L cells. Total RNA isolated from transfected cell lines was analyzed in a S1 nuclease assay. End-labeled single-stranded probes were homologous to sequences of the $5^{\prime}$ end of the human c-myc constructs. Probes homologous to the mouse GAPDH gene were included as an internal control. The diagram of transfected c-myc constructs containing deletions within the core promoter region is shown below. Solid arrows indicate the main sites of transcription initiation; open arrows indicate start sites detected after prolonged exposure of autoradiographs. (E2F) A binding site for the transcription activator E2F (Thalmeier et al. 1989). Single-stranded S1 probes extend from position +141 to the XhoI site at -95 of the c-myc wild-type sequence and were homologous for each construct except for $\triangle \mathrm{P} 1 \Delta \mathrm{P} 2 \mathrm{TATA}$, where the same probe as for $\triangle \mathrm{P} 1$ was used. Arrows indicate probes protected by c-myc RNA; the star indicates protected transcripts originating from sites upstream of the P2 initiation site. Although the deletion of both the TATA and the initiator sequence $(\Delta \mathrm{P} 1 \Delta-48 /+57)$ results in very little promoter-proximally paused RNA polymerase, full-length RNA can be detected in the absence of core promoter sequences. Further deletion of sequences up to -66 $(\Delta \mathrm{P} 1 \Delta-66 /+57)$ results in the loss of detectable full length RNA.

quence is not required for promoter-proximal pausing, suggesting that other elements are responsible or can substitute for TATA in setting up paused RNA polymerase complexes.
The high efficiency of transcription complex recruitment even in the absence of a TATA box is reminiscent of other highly active eukaryotic promoters lacking TATA sequences. These promoters contain initiator se- 
quences (Inr) that function efficiently to recruit and position RNA polymerase II complexes at the transcription initiation site (Smale and Baltimore 1989; for review, see Smale 1994). We noticed that the c-myc core promoter contains homologies to initiator sequences (Krumm et al. 1993). Similar to the HIV-LTR and the adenovirus major late promoter (Du et al. 1993), the c-myc transcription initiation region bears homologies to initiator sequences at two positions: sequences from -2 to +8 (Inrl) and +31 to +39 (Inr2). The Inr2 sequence is present in a reversed orientation relative to Inrl (Fig. 1C). To determine whether Inr-like elements within the c-myc core promoter function to recruit transcription complexes that are inefficient in elongation, we deleted either one or both Inr-like elements of the P2 promoter. Neither the deletion of a single Inr-like element (data not shown) nor the deletion of the region between positions -11 to +57 , encompassing both Inr-like elements, abolished promoter-proximal pausing (Fig. 1A). However, promoter-proximal pausing was not detectable in constructs where both the TATA consensus sequence and the Inr sequences (deletion from -48 to +57 ) were removed.

To correlate the level of transcriptional pausing with the production of full-length RNA, we performed S1 nuclease assays with probes derived from the $5^{\prime}$ end of each construct (Figs. 1D and 2B). [Results were confirmed with probes derived from exon 2 (data not shown).| To our surprise, full-length RNA is synthesized by deletion construct $\Delta \mathrm{P} 1 \Delta-48 /+57$, although no promoter-proximally paused RNA polymerase is detectable in nuclear run-ons. This result demonstrates that the c-myc upstream sequences can direct the synthesis of full-length RNA in the absence of recognizable TATA or Inr sequences. Similar amounts of full-length RNA are detected in wild-type and deletion constructs encompassing TATA $(\triangle \mathrm{P} 1 \Delta \mathrm{P} 2 \mathrm{TATA})$ and/or Inr sequences $(\Delta \mathrm{P} 1 \Delta-11 /+57, \Delta \mathrm{P} 1 \Delta-48 /+57)$. Analysis of steadystate RNA synthesized by the $\triangle \mathrm{P} 1 \Delta \mathrm{P} 2 \mathrm{TATA}$ construct revealed that transcription initiation occurred at multiple sites within a 30-bp region (Fig. 1D). A similar cluster of initiation sites has been observed in many other promoters lacking TATA sequences/Geng and Johnson 1993, and references therein). The synthesis of fulllength RNA may be dependent on the presence of sequences immediately upstream of -48 , as further deletion up to -64 abrogated synthesis of full-length RNA. The transcription factor E2F has been shown to bind to the c-myc upstream region at -60 to -66 and be required for c-myc expression (for review, see Spencer and Groudine 1990).

These results indicate that sequences necessary to generate high levels of promoter-proximally paused transcription complexes are located at the core promoter region of the c-myc gene. In addition, these results suggest that the level of promoter-proximal pausing is not correlated with the amount of full-length RNA. [It is formally possible that these results are influenced by different stabilities of the tested RNAs because of their different $5^{\prime}$ ends. However, the experiments presented below (Fig. 2B) and the report that $5^{\prime}$ sequences do not alter c-myc RNA stability (Bernstein et al. 1992) make this unlikely.]

Simple combination of Sp1 upstream activator and TATA/Inr sequences result in promoter-proximal pausing of $R N A$ polymerase

The results described above indicate that sequences within the c-myc core promoter are necessary for the generation of high levels of paused RNA polymerase. To test whether the simple combination of core promoter elements with upstream activators is sufficient to generate promoter-proximal pausing, we used synthetic constructs (Smale et al. 1990) containing Sp1-binding sites as upstream activators combined with TATA- or Inr sequences. Consistent with results obtained with constructs containing the c-myc promoter, only very little promoter-proximal pausing was observed in the absence of a TATA and absence of an Inr consensus sequence (SP1-MG; Fig. 2) The insertion of the c-myc Inr-like region from position -12 to +47 (SP1-INR-MG) or the terminal-deoxynucleotidyl-transferase gene (Tdt)-Inr (SP1-Tdt-MG) or the TATA consensus sequence of the adenovirus major late promoter (SP1-TATA-MG) increased the amount of promoter-proximal RNA polymerase II complexes $\sim 5$ - to 10 -fold. Similar to the results obtained with the c-myc gene, initiated complexes are very inefficient in elongation, and only little transcriptional activity is observed with run-on probes farther downstream. The deletion of upstream Spl sites $(\triangle S P 1-$ TATA-MG; Fig. 2A) or replacement with GAL4-DNAbinding sites (GAL-TATA-MG; data not shown) results in very little promoter-proximal pausing (see below).

These results indicate that the recruitment of high levels of paused RNA polymerase II complexes requires two components: (1) core promoter elements and (2) upstream-activating sequences. Either element alone generates very little promoter-proximal pausing; however, both elements together mediate a higher-than-additive degree of transcriptional initiation. Thus, the formation of high levels of initiation-competent but elongation deficient RNA polymerase II transcription complexes is attributable to a synergy between upstream activators and proteins associated with core promoter elements.

Analyses of steady-state RNA by S1 analysis confirmed results described above that the generation of full-length RNA is independent of the level of promoterproximal pausing. The construct without a consensus TATA or Inr sequence (SP1-MG) does not produce significantly less full-length RNA than the constructs containing elements of the c-myc, Tdt, or adenovirus major late core promoters displaying high promoter-proximal transcription (Fig. 2B).

Recruitment of elongation incompetent transcription complexes is a general property of transcriptional activators

The combination of TATA or Inr sequences with Spl 
A

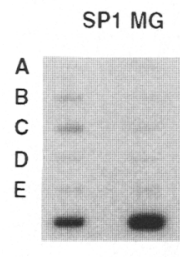

\section{SP1 INR MG}
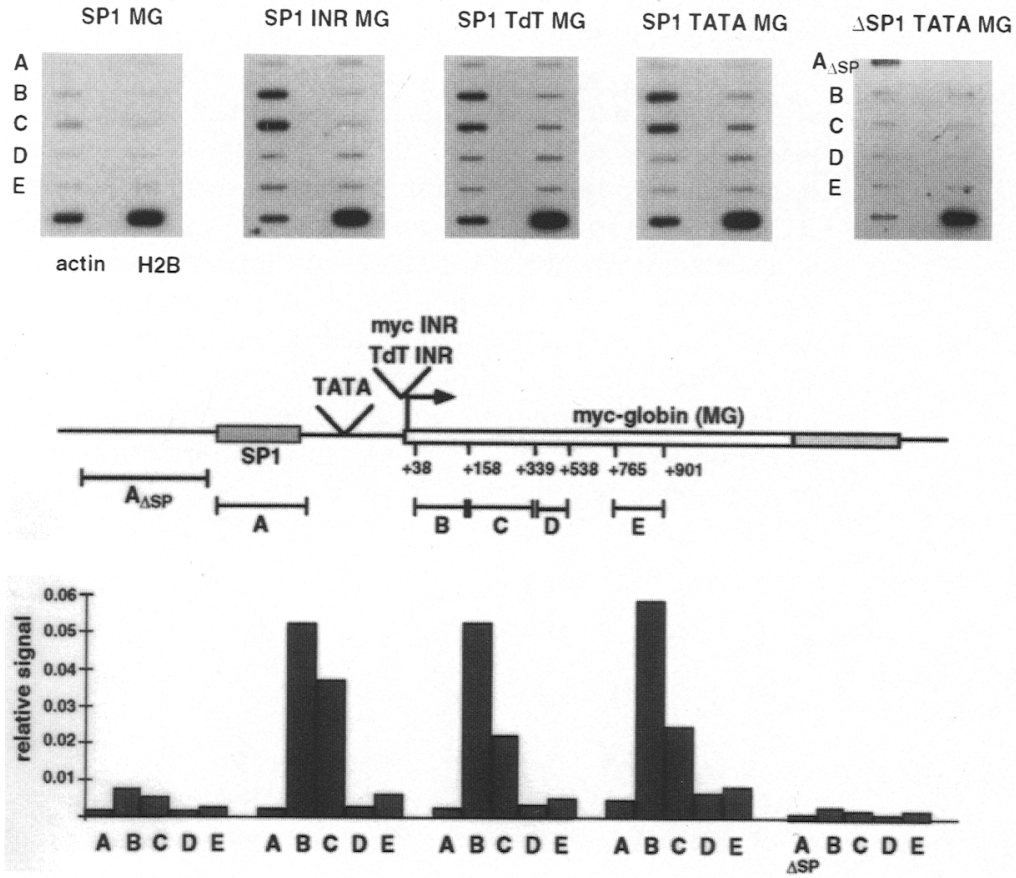

B
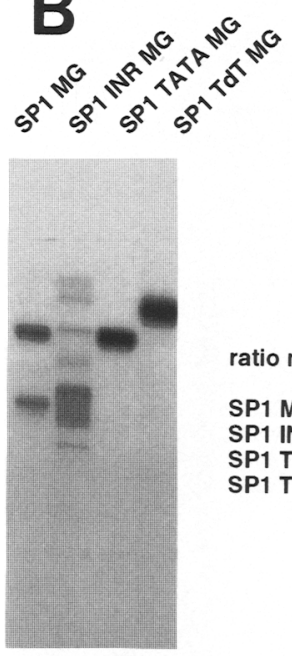

ratio myc-globin (MG)/GAPDH: SP1 MG SP1 INR MG SP1 TATA MG SP1 Tdt MG

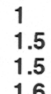

1.5

1.6

GAPDH
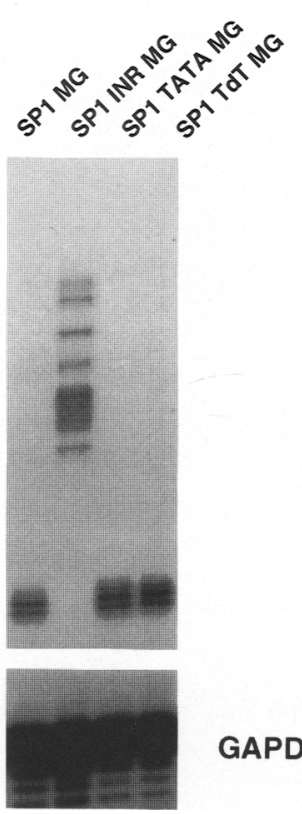

GAPDH
Figure 2. A simple promoter containing a core promoter element in conjunction with $\mathrm{Spl}$ as upstream activator is sufficient to set up paused RNA polymerase. Synthetic promoter constructs containing $12 \mathrm{Sp} 1$ upstream sites and either no core promoter element (SP1-MG) or a TATA consensus sequence derived from adenovirus major late promoter (SP1-TATA-MG) or initiator sequences from -11 to +47 of the c-myc gene (SP1-INRMG) or the Tdt gene (SP1-Tdt-MG) were combined with a hybrid reporter gene myc-globin (MG), and transfected into mouse $\mathrm{L}$ cells. $(A)$ Nuclear runon analyses of pools of stably transfected cells reveal that the formation of promoter-proximally paused transcription complexes can be observed in simple promoter constructs containing Spl upstream activators and core promoter elements. $(B)$ Nuclease S1 analyses of total RNA isolated from transfected polyclonal lines. (Left) End-labeled, single-stranded DNA probes are specific for each construct. Single-stranded probes were generated from different templates with the same oligonuleotide. Probes extend from +132 to -335 . (Right) $\mathrm{Nu}$ clease S1 analysis with a S1 probe homologous to SP1-INR-MG. This probe is only partially (from +38 to +132 ) homologous to transcripts derived from SP1-MG, SP1-TATA-MG, and SP1-TdTMG. The protected fragments of SPI-MG, SP1TATA-MG, and SP1-TdT-MG are of the same size and easier to quantify. Signals were counted with a PhosphorImager system and normalized to the amount of GAPDH. Although the level of RNA polymerase recruitment is increased 5-fold when TATA or Inr sequences are inserted, the steadystate levels of RNA are changed only 1.5 -fold. sites results in efficient recruitment of transcription complexes and a high level of RNA polymerases paused at promoter-proximal sites. Only a minor fraction of these complexes is detectable at sequences farther downstream. To investigate whether this phenomenon is limited to only Spl-driven promoters or whether this is a general property of many transcriptional activators, we tested several other trans-activators for their ability to recruit RNA polymerase II complexes and influence the elongation competence of these transcription complexes. To simplify these analyses, we used the GAL4 fusion system where trans-activation domains of different upstream activators are fused to the DNA-binding domain of the yeast trans-activator GAL4. High levels of strongly activating proteins, however, may inhibit the transcription of genes through "squelching" /Gill and Ptashne 1988). This negative, repressing effect has been observed with GAL4-VP16 fusion proteins (Sadowski et al. 1988). For this reason, stable integration of such constructs in L cells might result in selection of cell clones that express only minor amounts of the trans-activator. Thus, we analyzed recruitment of RNA polymerase II 

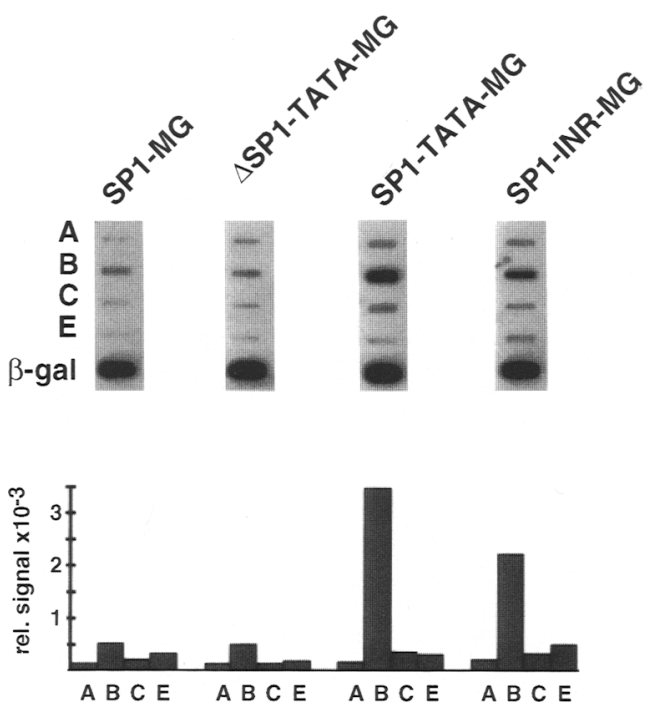

Figure 3. Recruitment of RNA polymerase II in synthetic promoter constructs after transient transfection. B78 cells were transfected with synthetic promoter constructs along with a $\beta$-gal gene driven by the CMV promoter as an internal control for transfection efficiency. Nuclear run-on assays confirm that in the absence of core promoter elements (SP1-MG; Fig. 2) or upstream activator elements ( $\triangle$ SP1-TATA-MG), only very little promoter-proximally paused RNA polymerase is detected. Insertion of TATA sequence or the $\mathrm{c}-\mathrm{myc}$ initiator region strongly increases the recruitment of RNA polymerases pausing within promoter-proximal regions.

and elongation efficiency after transient transfection into the murine melanoma cell line B78. In this cell line, expression of the endogenous c-myc gene is not detectable in nuclear run-on assays (data not shown). These cells reproduce faithfully the results obtained by stable transfections in $\mathrm{L}$ cells. Whereas constructs lacking a TATA box (SP1-MG) or upstream-activating sequences ( $\triangle$ SP1-TATA-MG) show very little promoter-proximal pausing, high levels of RNA polymerase II loading was obtained with constructs where a TATA box or the c-myc Inr sequence is combined with Spl upstream activators (Fig. 3).

To analyze the influence of different trans-activation domains on initiation and elongation, we replaced Sp1binding sites of our reporter construct SP1-TATA-MG with GAL4-binding sites. The resulting construct GALTATA-MG was transfected into B78 cells along with expression vectors coding for different trans-activation domains fused to the DNA-binding domain of the GAL4 protein; transcription of the cotransfected $\beta$-gal gene driven by the cytomegalovirus (CMV) promoter served as a control for transfection efficiency. When $B 78$ cells were transfected with GAL-TATA-MG, CMV- $\beta$-gal, and the "empty" vectors containing no trans-activating sequences, a low signal with all probes was detected. (The source of this background signal is possibly derived from cryptic initiation sites in vector sequences.) Note that the run-on signals were not increased when the expres- sion vector $\mathrm{pSG}(1-147)$ containing only the GAL4-DNAbinding domain was used, confirming that the GAL4DNA-binding domain itself is not sufficient to confer transcriptional activation in mammalian cells (Keegan et al. 1986; see Discussion). When the GAL4-SP1 hybrid proteins were coexpressed, the nuclear run-on signals obtained with promoter-proximal probes extending from +38 to +158 increased 10-fold (Fig. 4), indicating a high level of transcriptional initiation. A similar level of initiation was observed when GAL4 fusions of the transactivators MyoD, CTF, and Ela were analyzed. GAL4CCAAT/enhancer-binding protein (C/EBP), GAL4-p53, and GAL4-VP16 highly stimulated recruitment of RNA polymerase II complexes. All of these transcription activation domains, however, have in common that only a

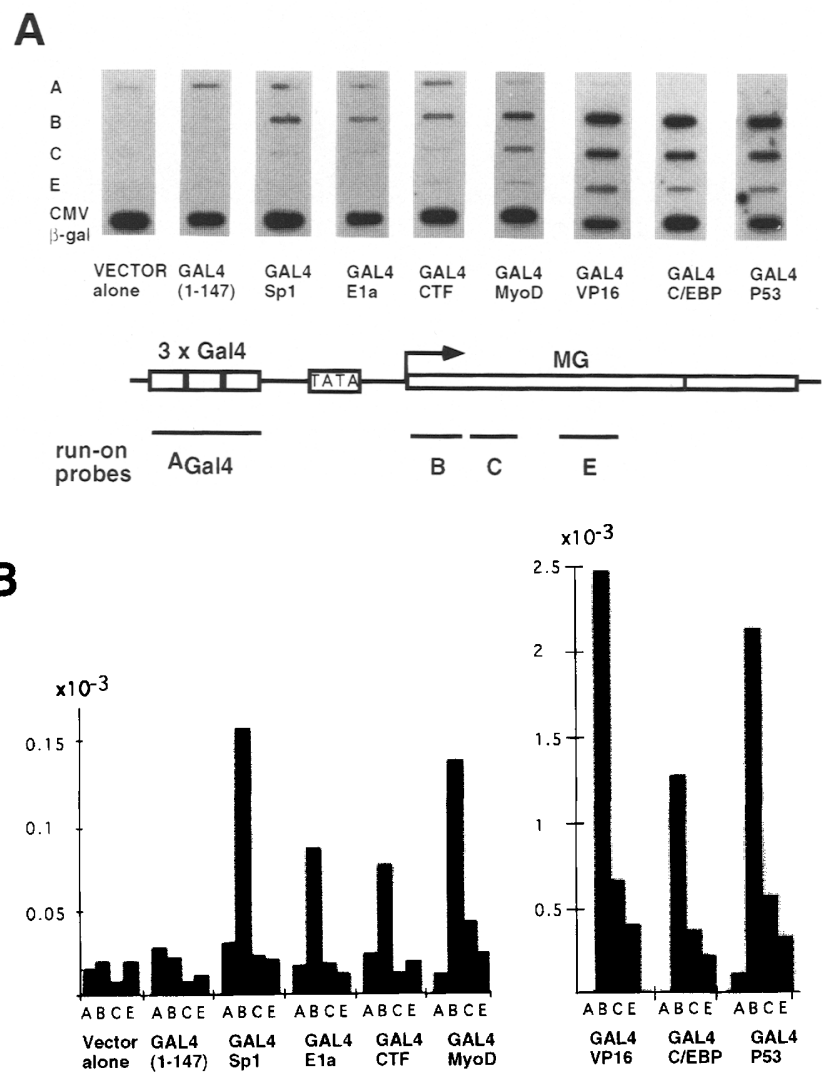

Figure 4. Different trans-activators support the formation of paused RNA polymerase. The Spl-binding sites of the SP1TATA-MG construct (Fig. 3) were substituted with GAL4-binding sites. This construct was transfected into B78 cells along with plasmids expressing GAL4 fusion proteins and the CMV$\beta$-gal control. $(A)$ The transfected cells were analyzed in nuclear run-on assays. The locations of single-stranded run-on probes $\mathrm{A}_{\mathrm{GAL} 4}$, and B-E are shown schematically. $(B)$ Quantification of run-on signals. Nuclear run-on signals were counted in a PhosphorImager system, corrected for the cytidine content, and normalized to the signal obtained with the probe specific for $\beta$-gal transcripts. Note the different scale for the $x$-axis of GAL4VP16, GAL4-p53, and GAL4-C/EBP trans-activated transcription. 
fraction of initiated transcription complexes transcribe into regions farther downstream. Thus, we conclude that pausing of transcription complexes in promoter-proximal regions is a common property of promoters driven by many different trans-activators.

\section{Enhancers influence elongation as well as initiation of transcription}

Our results indicate that the simple combination of upstream activator and core promoter element (TATA or Inr sequences) is sufficient to recruit high levels of RNA polymerase II complexes. However, the increased level of initiation in the presence of core promoter elements compared with constructs lacking core promoters does not result in a linear increase in the amount of steadystate RNA (see Fig. 2). Similar to this result, it has been reported that the activity of synthetic promoter constructs containing SP1-binding sites did not vary in the presence or absence of a TATA box (Wang and Gralla 1991). However, a higher level of activity was achieved when enhancers were added to the constructs, and this enhancer-mediated higher level of activity was dependent on the presence of TATA sequences. These results suggest that the recruitment of transcription complexes through upstream activator and TATA is a necessary prerequisite for the function of enhancers. Thus, we were interested in determining whether synergistic acti- vation of transcription relies on RNA polymerase II complexes already recruited through upstream activators and TATA or Inr elements. In this model, additional transactivators might help to recruit factors that allow elongation-incompetent transcription complexes to escape into regions farther downstream. This would result in a higher proportion of transcription complexes detectable in nuclear run-on assays in regions farther downstream.

Elongation competence of transcription complexes could also be determined by the characteristics of upstream activators. Although every trans-activator tested supports the formation of paused polymerase, they might differ in their ability to recruit factors necessary for efficient elongation of transcription complexes. These differences would become evident in the ratio of transcription complexes found farther downstream relative to transcription complexes found in promoter-proximal regions.

To determine whether enhancer sequences or upstream activators influence the elongation competence of transcription complexes, we introduced the SV40 enhancer (SVE) downstream of the Spl-TATA-MG construct (Fig. 5A). This construct, SP1-TATA-SVE, was assayed after transient transfection of B78 cells. In addition, we compared elongation efficiencies of RNA polymerase II complexes recruited by the highly efficient upstream activator GAL4-VP16.

Quantitative analyses of the steady-state mRNA lev-
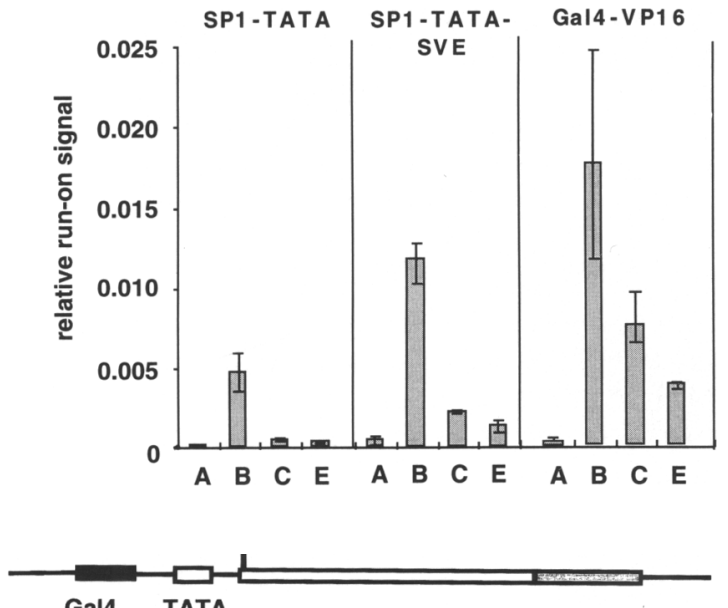

Gal4 TATA

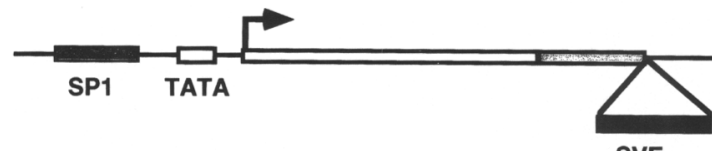

run-on probes

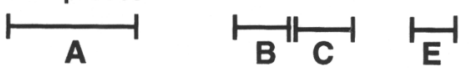

S1 probe

probe
B

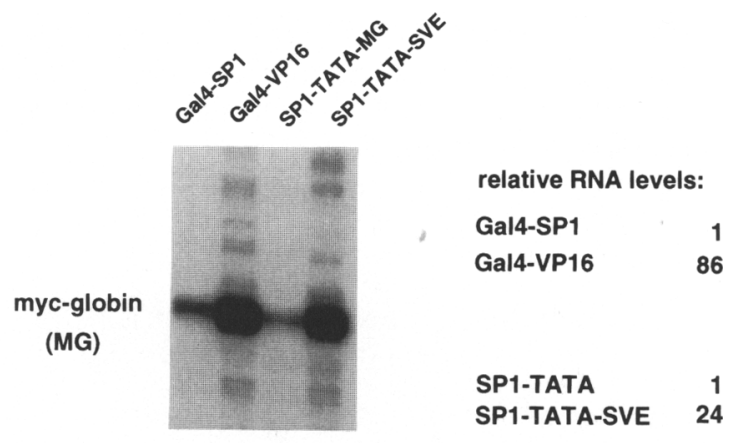

CMV B-gal
Figure 5. Enhancers greatly increase the amount of steady-state RNA, but not through suppression of the promoter-proximal pausing of RNA polymerase. $(A)$ The construct GAL-TATA-MG was transfected along with plasmids for expression of GAL4-SP1 or GAL4-VP16 trans-activators into B78 cells. The construct SP1-TATA-MG was compared with SP1-TATA-SVE /containing the SV40 enhancer downstream of the MG reporter gene) after transient transfection. $(B)$ Analysis of steady-state RNA in cells transfected with constructs shown in $A$. $(C)$ Quantitative analysis of three independent nuclear run-on experiments. Location of probes within the transfected gene is shown in $A$. Quantifications were done with the PhosphorImager system. 
els of transiently transfected SP1-TATA-SVE plasmids indicated a 20 -fold increase in reporter mRNA compared with the construct lacking enhancer sequences (Fig. 5B). Similarly, synthetic reporter gene constructs activated by GAL4-VP16 synthesized an average of 80 -fold more RNA than when activated by Spl in SP1-TATA-MG (Fig. 5B) or by GAL4-SP1 (data not shown). To analyze whether this increase was attributable to an increase in initiation or a release of RNA polymerase II complexes paused at promoter-proximal regions, we performed nuclear run-on assays. Each construct was tested at least three times in independent experiments. As shown in Figure 5C, the variation in these experiments was small. Nuclear run-on assays of cells transfected with SP1TATA-MG and SP1-TATA-SVE revealed a 2.5 -fold increase in RNA polymerase II recruitment by SVE, as indicated by the signal in the promoter-proximal probe $\mathrm{B}$, covering the region between +36 and +158 . GAL4VP16 stimulated recruitment of RNA polymerase II about 3.5-fold compared with Spl (Fig, 5C). To test whether the presence of enhancer sequences or strong upstream activators affects the release of RNA polymerase II complexes paused at promoter-proximal sites, the ratio of run-on signals of the promoter-proximal probe $B$ and the promoter-distal probe E was calculated (Fig. 5C). Constructs containing SVE sequences decreased the ratio of promoter-proximal to promoter-distal transcription complexes from 15:1 to $9: 1$, approximately twofold. The ratio for GAL4-VP16-activated transcription complexes was $5: 1$, corresponding to a threefold increase in transcription complexes in $3^{\prime}$ regions relative to promoter-proximal regions.

Thus, not only do enhancer sequences and highly active upstream activators increase the amount of transcription initiation, they also increase the elongation competence of RNA polymerase II complexes as suggested by previous results (Madisen and Groudine 1994; Yankulov et al. 1994). In addition, these results suggest that different activators may differ in the extent of their effect on elongation as well as initiation.

\section{Discussion}

\section{Sequences at the c-myc transcription initiation site are functionally equivalent to initiator elements}

The high nuclear run-on signal observed within c-myc exonl sequences is attributable to a high density of RNA polymerase II complexes in promoter-proximal regions. Recently, we have proposed that distinct promoter elements direct the assembly of RNA polymerase II complexes that differ in their elongation efficiency (Krumm et al. 1993). One such element has been described at the transcription initiation site of the HIV-LTR promoter and has been called inducer of short transcripts (IST). This element generates short transcripts within the HIV-LTR and has been shown to function even in the context of other RNA polymerase II or III promoters (Ratnasabapathy et al. 1990; Sheldon et al. 1993). Here, we provide evidence that sequences at the initiation site of the c-myc gene also contribute to the recruitment of high levels of elongation-deficient transcription complexes. In addition, we show that high levels of promoter-proximally paused transcription are not only the consequence of the presence of initiator sequences, but can also be conferred by consensus TATA sequences.

\section{Promoter-proximal pausing is a general feature of many promoters and may define a general rate- limiting step in transcription}

The analysis of the sequence requirements for formation of paused polymerase in the Drosophila hsp 70 gene revealed that upstream binding sites for the constitutively expressed GAGA factor are important elements in setting up paused polymerase in the $5^{\prime}$ region of the gene. Sequences around the transcriptional start site $(-12$ to +23 ) also seemed to influence pausing of RNA polymerase (Lee et al. 1992). Our results demonstrate that the simple combination of TATA sequences and upstream activators in synthetic promoter constructs is sufficient to generate a high level of promoter-proximally paused transcription complexes. Thus, this phenomenon is simply the result of synergistic interactions of regulatory factors and most likely occurs at many different promoters, rather than only at specialized promoters such as the c-myc or $h s p 70$ promoter.

The upstream activators Spl, CTF, MyoD, and Ela and especially VP16, C/EBP, and p53 stimulate high levels of transcription complex formation, but only a few of these complexes actually transcribe regions farther downstream. Of the activators tested, GAL4-VP16 appeared to have the greatest positive effect on elongation competence. However, we did not observe complete suppression of promoter-proximal pausing by the VP16 trans-activation domain as reported previously (Yankulov et al. 1994). The most likely basis for these different observations is the different characteristics of the systems used in the analyses. For example, in our experiments (see Fig. 4), as well as in vitro (Wang et al. 1992; White et al. 1992), GAL4-VP16 highly stimulates recruitment of RNA polymerase II complexes to the promoter. However, in the system described by Yankulov et al., GAL4-VP16 does not increase transcription initiation significantly when compared with the GAL4-DNA-binding domain alone. Our experiments suggest that the acidic domain of VP16 enhances formation of the initiation complex $\geqslant 60$-fold higher than the GAL4-DNA-binding domain alone. Most of the transcription complexes, however, are paused at a promoter-proximal position.

Promoter-proximal pausing may define a common step in transcriptional activation, as it is observed with many promoters and different trans-activators. Although different trans-activators differ in the level of transcription complex recruitment, they are similar in that the highest amount of polymerase is detected at or close to the initiation site. Resistance to Sarkosyl indicates that these RNA polymerase II complexes are already initiated (Krumm et al. 1992). Thus, the major rate-limiting step in transcription in vivo seems to occur at a step after 
transcription initiation. The polarity of RNA polymerase II density may be indicative of an antitermination mechanism, such as observed in prokaryotes at the $\lambda \mathrm{pR}^{\prime}$ promoter, where the $\mathrm{Q}$ protein is required by RNA polymerase to escape out of the promoter-proximal pause at position +16 (for review, see Roberts 1993). Similarly, efficient elongation of several Drosophila genes in vitro has been shown to depend on the presence of the positive elongation factor P-TEF. This factor has been shown to convert termination-prone transcription complexes into elongation-efficient transcription complexes (Kephard et al. 1992; Marshall and Price 1992).

In many aspects, promoter-proximal pausing resembles promoter clearance, which has been shown to influence transcription of genes in both prokaryotes and eukaryotes (Jacob et al. 1994 and references therein). Recently, it has been suggested that the two general transcription factors TFIIE and TFIIH are not required for transcription initiation, but are necessary for promoter clearance (Goodrich and Tjian 1994; Maxon et al. 1994). Thus, the high level of paused transcription complexes at promoter-proximal regions may be attributable to the lack of TFIIE and TFIIH at initiated complexes. The release of paused complexes may be regulated through recruitment of these general transcription factors. The interaction of these factors with the paused transcription complex may result in the phosphorylation of the carboxy-terminal domain (CTD) domain of RNA polymerase II. Different levels of CTD phosphorylation have been shown to be associated with paused and elongating RNA polymerase II complexes at the $h s p 70$ and other genes in Drosophila (Weeks et al. 1993; O'Brien et al. 1994). In this context, it is important to note that some transcriptional trans-activators such as GAL4-VP16 and GAL4-p53 have been reported to bind to TFIIH (Xiao et al. 1994).

Alternatively, promoter-proximal pausing may be attributable to abortive initiation mechanisms. This model differs from the antitermination model discussed above in that pausing or terminating transcription complexes may not be converted into "readthrough" transcription complexes; rather, the generation of full-length RNA requires de novo initiation where distinct promoter elements necessary for efficient elongation of the transcription complex recruit factors to the initiation or early elongation complex (see Krumm et al. 1993 for further discussion).

\section{Transcriptional synergy functions at both levels, initiation and elongation}

High mRNA levels are obtained through synergistic interaction of multiple upstream activators. Transcriptional synergy refers to the greater than additive increase in transcription when more than one type of trans-activator is present or when additional binding sites are added. The basic mechanism underlying synergism remains unknown. The mechanism could be attributable to cooperativity in binding of trans-activators. Cooperative binding is not always observed on naked DNA tem- plates and in some cases requires DNA packaged into chromatin (Workman et al. 1991; Croston et al. 1992; Chang and Gralla 1994). However, synergistic activation has been observed under conditions where the binding sites of the activator are saturated (Carey et al. 1990; Lin et al. 1990). This result supports the idea that synergizing trans-activators may catalyze different steps during transcription complex assembly (for review, see Herschlag and Johnson 1993). For example, the ability of the trans-activator VP16 to interact with both TFIID and TFIIB may explain the synergistic response obtained with promoters containing more than one binding site. One molecule could catalyze the binding of TFIID, whereas the other molecule could increase the efficiency of TFIIB recruitment or stabilize its binding. Here we demonstrate a different level of transcriptional synergy. Whereas the upstream activator stimulates the recruitment of RNA poymerase II complexes, additional transactivators recruited through enhancer sequences confer elongation efficiency to the transcription complexes. Thus, transcriptional synergy may be obtained by facilitating sequential steps at initiation and elongation of transcripts.

In a recent study, it has been shown that multiple activators increase the amount of TFIIE loaded into the transcription complexes (Choy and Green 1993). As mentioned above, TFIIE as well as TFIIH have been suggested to be essential for promoter clearance rather than for formation of functional initiation complexes. Thus, it is possible that RNA polymerase II complexes recruited through proximal upstream activators are devoid of TFIIE or TFIIH, leading to inefficient promoter clearance. During the nuclear run-on assay, however, these polymerases are released to transcribe regions farther downstream, even in the absence of above mentioned "clearance" factors.

The recruitment of transcription complexes through interaction of the $\mathrm{Sp} 1$ upstream activator with elements of the core promoter is synergistical itself. The combination of upstream activator and TATA or Inr sequence recruit much higher levels of transcription complexes than either element alone. These complexes are very inefficient at the elongation phase of transcription. Additional factors seem to be required to render these complexes elongation efficient or to recruit elongation-efficient RNA polymerase II complexes de novo.

\section{Elongation rate as an important mechanism for gene regulation}

The increase in the level of full-length RNA in the presence of upstream activators and enhancers does not correspond to the observed modest increase in transcriptional initiation. Although efficient trans-activators and enhancers can increase the amount of transcription complexes detected farther downstream relative to the amount of RNA polymerase II complexes at the promoter (this study; Madisen and Groudine 1994; Yankulov et al. 1994), the much higher level of full-length RNA is not simply explained by the relief of pausing near the 
promoter. The release of promoter-proximally stalled RNA polymerase II complexes would be expected to result in a proportional increase of run-on signals detected with downstream probes. However, in most cases, this has not been observed. Formally, this discrepancy could be explained by limitations of the run-on assay, including the possible failure of downstream RNA polymerases to resume transcription in this assay. Alternatively, enhancers/activators may increase the rate of transcription complex elongation by decreasing or suppressing pausing of RNA polymerase II complexes once they are out of the promoter-proximal region. Transcription complexes that pass through the gene at a very high rate would be difficult to detect, as the average time spent transcribing the template would be reduced drastically. Thus, although strong upstream activators and enhancers examined in this study confer modest increases in initiation and release of polymerase from the promoter-proximal pause site, we propose that they also influence gene activity through modulating the elongation rate of the transcription complex.

Elongation rates are influenced by different mechanisms. For example, nucleosomes have been described to impede transcriptional elongation (Izban and Luse 1991). Recently, HMG-14, a nonhistone chromosomal protein, has been reported to increase transcriptional elongation about fourfold in in vitro transcription reactions on nucleosomal templates (Ding et al. 1994). Although HMG14 and other nonhistone proteins are abundant nuclear proteins, some are found only in transcriptionally active regions (Weisbrod et al. 1980). In in vitro transcription experiments, the general transcription factor TFIIF has been reported to function at the level of elongation and was proposed to act as a processivity factor through suppression of pause sites of polymerase complexes, thereby increasing the rate of transcription (Bengal et al. 1991). Regulation at the level of elongation rate has also been suggested to be responsible for modulation of RNA levels from the HIV-LTR promoter (Kato et al. 1992). In this study, Tat has been described as a factor cooperating with and stimulating the activity of the elongation factor TFIIF.

\section{A general model for the postinitiation control of transcription}

With the evidences available from several studies, the following model may describe the regulation of transcription at the level of elongation (Fig. 6). High levels of RNA polymerase II complexes are recruited through the synergistic action of upstream activator and TATA/Inr sequences. Initiated transcription complexes pause at or immediately downstream of the transcription initiation site. Upon modification, transcription complexes are released into downstream regions. This modification may involve the general transcription factors TFIIE and TFIIH, both suggested to be required for promoter clearance. The interaction of promoter-proximal transcription complexes with these general transcription factors may result in (re)phosphorylation of the CTD of RNA polymerase II. Alternatively, as discussed above, the modification of the transcription complex may occur before initiation of transcription. Partly assembled RNA polymerase complexes lacking the general transcription factors TFIIE and TFIIH or others may initiate transcription, however, pause and finally terminate within promoter-proximal regions. Only completely assembled transcription complexes generate full-length RNA. An additional level of transcriptional control may be exerted through modulation of elongation rates. This mechanism may function at the level of chromatin structure/ accessibility and factors suppressing idling of RNA polymerase II complexes at intrinsic pause sites.

The proposed model could account for many observations made in several systems where transcriptional synergy has been observed. For instance, transcriptional activation of the HIV type 1 promoter involves synergy between the viral Tat protein and Spl (Southgate and Green 1991; Kamine and Chinnadurai 1992). Whereas the deletion of NF-kB sites results only in a modest decrease in transcription, deletion of Spl-binding sites results in a drastic reduction of Tat trans-activation (Kamine et al. 1991). The HIV core promoter $(-43$ to +80$)$ cannot be induced by Tat even in the presence of the trans-activation response (TAR) sequence. Moreover, the simple addition of synthetic upstream activator motifs (Spl, Oct, and others) confer Tat responsiveness (Berkhout and Jeang 1992). In addition, trans-activation by Tat requires the HIV-TATA motif (Garcia et al. 1989; Olsen and Rosen 1992; Lu et al. 1993). These experiments could be interpreted to confirm the simple model of promoter structure proposed in this study, where the combination of TATA sequences and upstream activators are necessary to recruit high levels of transcription complexes. In the absence of those promoter elements, the promoter is still functional and generates basal levels of full-length RNA; however, this promoter cannot respond to induction signals required to recruit transcription complexes highly efficient in elongation. In the case of the HIV-LTR, this signal would be provided by or mediated through the binding of Tat protein to the TAR. In general, for most promoters, trans-activators recruited by enhancers or upstream sequences, or both, may determine the elongation competence of the transcription complex.

\section{Materials and methods}

Plasmids and M13 constructs

The $\mathrm{p} \Delta \mathrm{P} 1 \mathrm{c}-\mathrm{myc}$ construct from which the P1TATA box through the Pl cap site are deleted has been described previously (Spencer et al. 1990). This construct contains an intact P2 promoter and is used in this study as the "wild-type" promoter. To construct $\mathrm{p} \Delta \mathrm{P} 1 \Delta \mathrm{P} 2 \mathrm{TATA}$, the $X h o \mathrm{I}-\mathrm{XbaI}$ fragment of $\mathrm{p} \Delta \mathrm{P} 1$ was substituted with the same fragment of $\mathrm{p} \Delta \mathrm{P} 2 \mathrm{TATA}$ (Spencer et al. 1990) containing a deletion of the sequence TATA upstream of the c-myc P2 transcription initiation site. Core promoter deletions were generated by cutting linker-scanner mutants $\mathrm{p} \Delta \mathrm{P} 1 L S 12, \mathrm{p} \Delta \mathrm{P} 1 \mathrm{LS} 7$, and $\mathrm{p} \Delta \mathrm{P} 1 \mathrm{LS} 4$ (Meulia et al. 1992) with EcoRI and SapI, and religating the ends after filling in with 


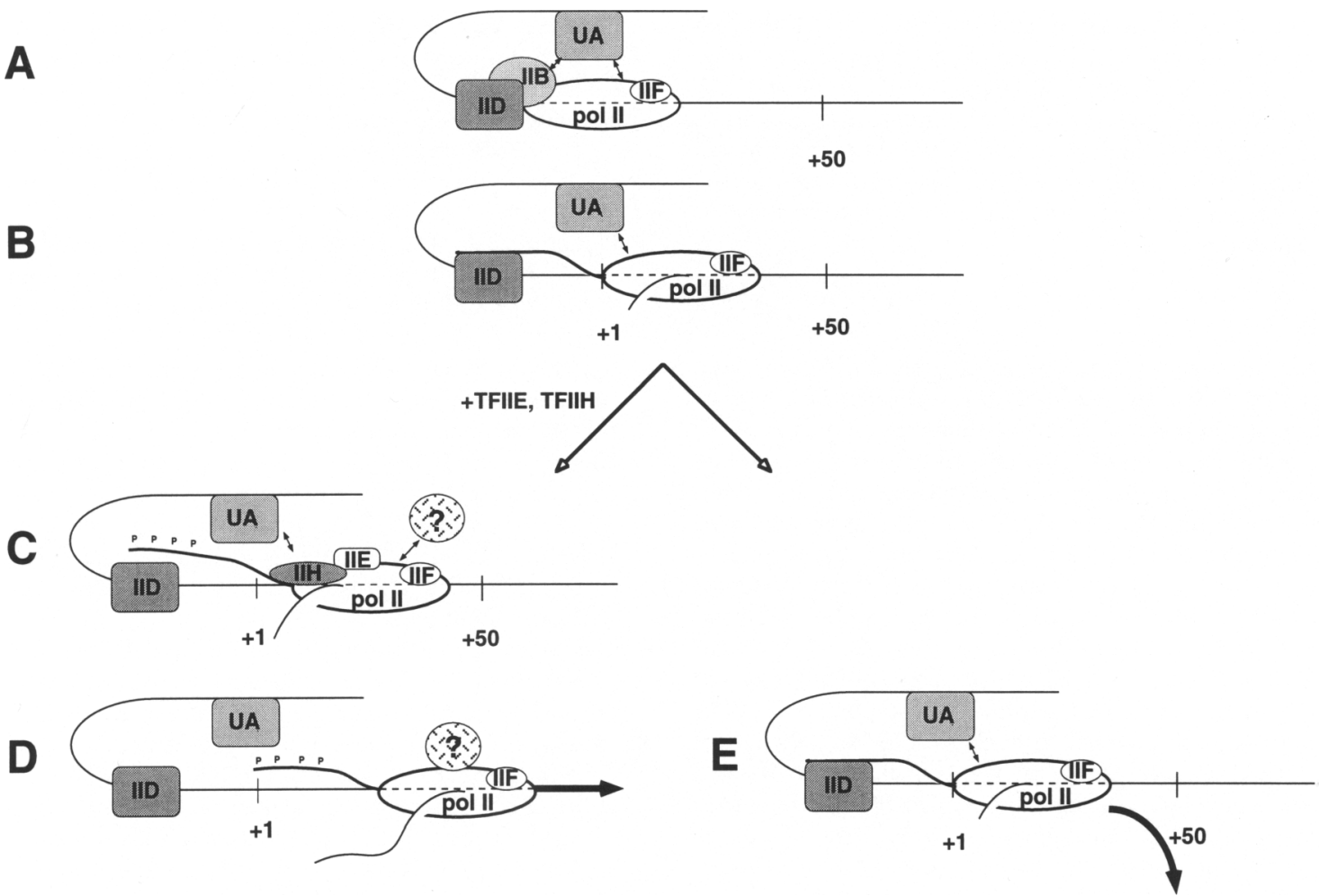

Figure 6. Model describing transcriptional regulation at the level of promoter-proximal pausing. (A) Preinitiation complex is formed through interaction of upstream activator with general transcription factors TFIID and TFIIB. (B) After initiation the transcription complex is paused at sequences around +30 , possibly through interaction of the transcribing complex with TFIID through the CTD domain with upstream activators. $(C)$ Recruitment of TFIIE and TFIIH through upstream activators results in phosphorylation of the CTD and disruption of the TFIID-CTD interaction. Additional factors (?) may be loaded to render the transcription complex resistant to intrinsic pausing signals further downstream, thereby increasing the elongation rate. $(D)$ RNA polymerase complex leaving the promoter to generate full-length RNA. $\{E \mid$ The failure to recruit TFIIE and TFIIH or additional factors $(?)$ may result in termination of transcription.

T4 polymerase. Synthetic promoter constructs containing Sp1binding sites alone (plasmid III; Smale et al. 1990), or in addition to a TATA box derived from the adenovirus major late promoter (plasmid V; Smale et al. 1990), or the initiator region of the Tdt (plasmid VI; Smale et al. 1990). To insert sequences of the c-myc transcription initiation site, plasmid III was cut with EcoRI and SmaI and the EcoRI-NaeI fragment (sequences -11 to +47 relative to the P2 promoter) of the linker-scanner plasmid $\mathrm{p} \Delta$ P1LS12 (Meulia et al. 1992) was inserted. As a reporter gene, the HindIII-MscI fragment of the fusion gene myc-globin (MG) was cloned into the HindIII and PvuII site of the synthetic promoter constructs to obtain SP1-MG, SP1-TATA-MG, SP1Tdt-MG, and SP1-Inr-MG. $\triangle$ SP1-TATA-MG was generated through excision of the HpaI-BgIII fragment containing the binding sites for upstream activator Sp1. SP1-TATA-SVE was constructed through insertion of a HincII fragment of pCATcontrol (Promega) containing the SV40 enhancer into the AatII site, downstream of the MG reporter of SP1-TATA-MG. GAL4 promoter construct GAL4-TATA-MG was constructed through excision of Spl-binding sites by $\mathrm{HpaI}$ and $\mathrm{BglII}$, and insertion of a 79-bp SmaI-SauIIIA fragment of pSH384 (gift of S. Hahn) containing three GAL4-binding sites.

GAL4 expression plasmids GAL4(1-147), GAL4-VP16, GAL4-Sp1, GAL4-P53, and GAL4-CTF were provided by C. Chang and J. Gralla, GAL4-Ela by M. Green, GAL4-MyoD by H. Weintraub.

\section{Cell lines and transfection}

The mouse $\mathrm{L}$ cell fibroblast line and the melanoma cell line B78 were cultured in Dulbecco's modified Eagle medium (DMEM) with $10 \%$ bovine calf serum and $2 \mathrm{~mm}$ glutamine.

Mouse L cells were transfected by electroporation as described (Krumm et al. 1992). B78 cells were transfected by the calcium phosphate precipitation method (Sambrook et al. 1989). For a $15-\mathrm{cm}$ dish, a total of $27.5 \mu \mathrm{g}$ plasmid DNA was used. Briefly, a $25-\mu$ g of reporter plasmid (or a $18 \mu \mathrm{g}$ of GAL4-TATA$M G$ in addition to a 7- $\mu$ g GAL4 trans-activator expression plasmid) were combined with a $2.5-\mu \mathrm{g} C M V$-gal plasmid as a transfection control and combined with $660 \mu \mathrm{l} 0.1 \times \mathrm{TE}[1 \mathrm{mM}$ Tris- $\mathrm{HCl}(\mathrm{pH} 8)$, and $0.1 \mathrm{mM}$ EDTA], $750 \mu \mathrm{l} 2 \times \mathrm{HBS}(280 \mathrm{mM}$ $\mathrm{NaCl}, 10 \mathrm{mM} \mathrm{KCl}, 1.5 \mathrm{mM} \mathrm{Na}_{2} \mathrm{HPO}_{4}, 2 \mathrm{H}_{2} \mathrm{O}, 12 \mathrm{mM}$ dextrose, 50 mM HEPES). After addition of $93 \mu 12 \mathrm{M} \mathrm{CaCl}_{2}$, the solution was added to a $15-\mathrm{cm}$ dish containing $2 \times 10^{6}$ cells. After incubation overnight, the cells were washed with Tris and fed with fresh DMEM medium. Twenty-four hours later, cells were harvested and nuclei or RNA were prepared.

\section{RNA and DNA analyses}

Total RNA for S1 protection analyses was isolated from cells with RNAzol (Cinna/Biotecx) according to the manufacturer's protocol. 5' End-labeled probes were generated by extension of 
an oligonucleotide, phosphorylated with T4-kinase and $\left[\gamma^{-32} \mathrm{P}\right] \mathrm{ATP}$, in a 14 -cycle PCR reaction on linearized doublestranded plasmid DNA (5 $\mu \mathrm{g})$. End-labeled single-stranded DNA was isolated on a $6 \%$ acrylamide gel. The mouse GAPDH probe is decribed in Madisen and Groudine (1994). Hybridization of single-stranded probe with total RNA was performed as described (Meulia et al. 1992). Southern analyses were done as decribed (Sambrook et al. 1989).

\section{Nuclear run-on analyses}

Nuclear run-on assays were done as described (Krumm et al. 1992) with the following modifications: After DNase I treatment of nuclei and proteinase $\mathrm{K}$ treatment for $20 \mathrm{~min}$ at $55^{\circ} \mathrm{C}$, RNA was purified with two phenol-chloroform (1:1) extractions. Labeled RNA was precipitated with three volumes of ethanol, resuspended in TE, and separated from unincorporated nucleotides by use of a Sephadex G50 column. Run-on assays with nuclei of transiently transfected B78 cells were performed with $\left[\alpha^{-32}\right.$ P $]$ CTP. Control experiments with HL60 cells and transfected $\mathrm{L}$ cells revealed no difference whether $\left[\alpha-{ }^{32} \mathrm{P}\right] \mathrm{UTP}$ or $\left[\alpha^{-{ }^{32}} \mathrm{P}\right] \mathrm{CTP}$ was used as the label. M13 probes A-E of regions of the $c-m y c$ gene as hybridization probes correspond to $\mathrm{P}_{\mathrm{o}}, \mathrm{SR}$, NS, RS, and SA probes described in Krumm et al. (1992). The probes $A_{s p 1}$ used to detect upstream transcription in Sp1-driven promoters was generated through subcloning of a $0.3-\mathrm{kb} H \mathrm{HpII}-$ BgIII fragment into M13 mp18 and M13 mp19. The $A_{\mathrm{Gal}}$ probe detecting upstream transcripts in the GAL4-TATA-MG construct was excised from pSH384 with SmaI (see above).

\section{Acknowledgments}

We thank Mary Peretz and David Dickey for excellent technical assistance in the transfection experiments and growth of cells, and Lee James for his help in the modification of synthetic promoters. We are very grateful to Stephen Smale who generously provided us with synthetic promoter constructs, and to Chenbei Chang, Jay Gralla, and M. Green who provided us with Gal4 expression vectors. We also thank Steve Hahn, Ron Reeder, Hal Weintraub, and our colleagues in the Groudine laboratory for critical comments and suggestions concerning this manuscript. This work was supported by National Cancer Institute grant CA54337 to M.G. and by a Special Fellowship from the Leukemia Society of America to A.K.

The publication costs of this article were defrayed in part by payment of page charges. This article must therefore be hereby marked "advertisement" in accordance with 18 USC section 1734 solely to indicate this fact.

\section{Note added in proof}

After this paper was in press, Zhou and Sharp [EMBO $J$. (1995) 14: 321-328], investigating the transcriptional activation of the HIV-LTR in vitro, reported results supporting the view that upstream activators in combination with TATA sequences recruit high levels of elongation-deficient transcription complexes, and additional signals are required to render these complexes elongation efficient.

\section{References}

Bengal, E., O. Flores, A. Krauskopf, D. Reinberg, and Y. Aloni. . 1991. Role of transcription factors IIF, IIS and IIX during elongation by RNA polymerase II. Mol. Cell. Biol. 11: 11951206.
Bentley, D.L. and M. Groudine. 1986. A block to elongation is largely responsible for decreased transcription of c-myc in differentiated HL60 cells. Nature 321: 702-706.

Berkhout, B. and K. Jeang. 1992. Functional roles for the TATA promoter and enhancers in basal and Tat-induced expression of the human immunodeficiency virus type 1 long terminal repeat. J. Virol. 66: 139-149.

Bernstein, P.L., D.J. Herrick, R.D. Prokipcak, and J. Ross. 1992. Control of c-myc mRNA half-life in vitro by a protein capable of binding to a coding region stability determinant. Genes \& Dev. 6: 642-654.

Carey, M., Y. Lin, M. Green, and M. Ptashne. 1990. A mechanism for synergistic activation of a mammalian gene by Gal4 derivatives. Nature 345: 361-364.

Chang, C. and J.D. Gralla. 1994. A critical role for chromatin in mounting a synergistic transcriptional response to Gal4VP16. Mol. Cell. Biol. 14: 5175-5181.

Choy, B. and M. Green. 1993. Eukaryotic activators function during multiple steps of preinitiation complex assembly. Nature 366: 531-536.

Croston, G.E., L.A. Kerrigan, L.M. Lira, D.R. Marshak, and J.T. Kadonaga. 1992. Mechanism of transcriptional antirepression by GAL4-VP16. Genes \& Dev. 6: 2270-2281.

Cullen, B.R. 1993. Does HIV-1 Tat induce a change in viral initiation rights? Cell 73: 417-420.

Ding, H., S. Rimsky, S.C. Batson, M. Bustin, and U. Hansen. 1994. Stimulation of RNA polymerase II elongation by chromosomal protein HMG-14. Science 265: 796-799.

Du, H., A.L. Roy, and R.G. Roeder. 1993. Human transcription factor USF stimulates transcription through the initiator elements of the HIV-1 and the AdML promoters. EMBO J. 12: $501-510$.

Eick, D. and G.W. Bornkamm. 1986. Transcriptional arrest within the first exon is a fast control mechanism in the c-myc gene expression. Nucleic Acids Res. 14: 8331-8345.

Garcia, J.A., D. Harrich, E. Soultanakis, F Wu, R. Mitsuyasu, and R.B. Gaynor. 1989. Human immunodeficiency virus type 1 LTR TATA and TAR region are required for transcriptional regulation. $E M B O J$. 8: 765-778.

Geng, Y. and L.F. Johnson. 1993. Lack of an initiator element is responsible for multiple transcriptional initiation sites of the TATA-less mouse thymidylate synthase promoter. Mol. Cell. Biol. 13: 4894-4903.

Giardiana, C., M. Perez-Riba, and J.T. Lis. 1992. Promoter melting and TFIID complexes on Drosophila genes in vivo. Genes \& Dev. 6: 2190-2200.

Gill, G. and M. Ptashne. 1988. Negative effect of the transcriptional activator GAL4. Nature 334: 721-724.

Goodrich, J.A. and R. Tjian. 1994. Transcription factors IIE and IIH and ATP hydrolysis direct promoter clearance by RNA polymerase II. Cell 77: 145-156.

Greenblatt J., J.R. Nodwell, and S.W. Mason. 1993. Transcriptional antitermination. Nature 436: 401-406.

Herschlag, D. and F.B. Johnson. 1993. Synergism in transcriptional activation: A kinetic vew. Genes \& Dev. 7: 173-179.

Izban, M.G. and D.S. Luse. 1991. Transcription on nucleosomal templates by RNA polymerase II in vitro: Inhibition of elongation with enhancement of sequence specific pausing. Genes \& Dev. 5: 683-696.

Jacob G.A., J.A. Kitzmiller, and D.S. Luse. 1994. RNA polymerase II promoter strength in vitro may be reduced by defects at initiation or promoter clearance. I. Biol. Chem. 269: 36553663.

Kamine, J. and G. Chinnadurai. 1992. Synergistic activation of the human immunodeficiency virus type 1 promoter by the viral Tat protein and cellular transcription factor Spl. J. Vi- 
rol. 66: 3932-3936.

Kamine, J., T. Subramanian, and G. Chinnadurai. 1991. Sp1dependent activation of a synthetic promoter by human immunodeficiency virus type 1 Tat protein. Proc. Natl. Acad. Sci. 88: 8510-8514.

Kao, S.Y., A.F. Calman, P.A. Luciw, and B.M. Peterlin. 1987. Anti-termination of transcription within the long terminal repeat of HIV-1 by tat gene product. Nature 330: 489-493.

Kato, H., H. Simimoto, P. Pognonec, C.H. Chen, C.A. Rosen, and R.G. Roeder. 1992. HIV-1 Tat acts as a processivity factor in vitro in conjunction with cellular elongation factors. Genes \& Dev. 6: 655-666.

Keegan, L., G. Gill, and M. Ptashne. 1986. Separation of DNA binding from the transcription-activating function of eukaryotic transcriptional activator protein. Science 231: 699704.

Kephart, D.D., N.F. Marshall, and D.H. Price. 1992. Stability of Drosophila RNA polymeraseII elongation complexes in vitro. Mol. Cell. Biol. 12: 2067-2077.

Krumm, A., T. Meulia, M. Brunvand, and M. Groudine. 1992. The block to transcriptional elongation within the human c-myc gene is determined in the promoter-proximal region. Genes \& Dev. 6: 2201-2213.

Krumm, A., T. Meulia, and M. Groudine. 1993. Common mechanism for the control of eukaryotic transcriptional elongation. BioEssays 15: 659-665.

Laspia, M.F., A.P. Rice, and M.B. Mathews. 1989. HIV-1 Tat protein increases transcriptional initiation and stabilizes elongation. Cell 59: 283-292.

Lee, H., K.W. Kraus, M.F. Wolfner, and J.T. Lis. 1992. DNA sequence requirements for generating paused polymerase at the start of hsp70. Genes \& Dev. 6: 284-295.

Lin, Y., M. Carey, M. Ptashne, and M. Green. 1990. How different eukaryotic transcriptional activators can cooperate promiscuously. Nature 345: 359-361.

Lis, J. and C. Wu. 1993. Protein traffic on the heat shock promoter: Parking, stalling, and trucking along. Cell 74: 1-4.

Lu, X., T.M. Welsh, and B.M. Peterlin. 1993. The human immunodeficiency virus type 1 long terminal repeat specifies two different transcription complexes, only one of which is regulated by Tat. J. Virol. 67: 1752-1760.

Madisen, L. and M. Groudine 1994. Identification of a locus control region in the immunoglobulin heavy-chain locus that deregulates c-myc expression in plasmacytoma and Burkitt's lymphoma cells. Genes \& Dev. 8: 2212-2226.

Marshall, N.F. and D.H. Price. 1992. Control of formation of two distinct classes of RNA polymerase II elongation complexes. Mol. Cell. Biol. 12: 2078-2090.

Mason, S.W., J. Li, and J. Greenblatt. 1992. Host factor requirements for processive antitermination of transcription and suppression of pausing by the $\mathrm{N}$ protein of bacteriophage $\lambda$. J. Biol. Chem. 267: 19418-19426.

Maxon, M.E., J.A. Goodrich, and R. Tjian. 1994. Transcription factor IIE binds preferentially to RNA polymerase Iia and recruits TFIIH: A model for promoter clearance. Genes \& Dev. 8: 515-524.

Meulia, T., A. Krumm, C. Spencer, and M. Groudine. 1992. Sequences in the human c-myc P2 promoter affect the elongation and premature termination of transcripts initiated in the upstream Pl promoter. Mol. Cell. Biol. 12: 4590-4600.

Meulia, T., A. Krumm, and M. Groudine. 1993. Distinct properties of c-myc transcriptional elongation are revealed in Xenopus oocytes and mammalian cells and by template titration, 5,6-Dichloro-1- $\beta$-D-Ribofuranosylbenzimidazole (DRB), and promoter mutagenesis. Mol. Cell. Biol. 13: 56475658.
Nepveu, A. and K.B. Marcu. 1986. Intragenic pausing and antisense transcription within the murine c-myc locus. EMBO $/$. 5: $2859-2865$.

O'Brien, T. and J.T. Lis. 1991. RNA polymerase II pauses at the $5^{\prime}$ end of the transcriptionally induced Drosophila hsp70 gene. Mol. Cell. Biol. 11: 5285-5290.

O'Brien, T., S. Hardin, A. Greenleaf, and J. Lis. 1994. Phosphorylation of RNA polymerase II C-terminal domain and transcriptional elongation. Nature 370: 75-77.

Olson, H.S. and C.A. Rosen. 1992. Contribution of the TATA motif to Tat-mediated transcriptional activation of human immunodeficiency virus gene expression. J. Virol. 66: 55945597.

Rasmussen, E.B. and J. Lis. 1993. In vivo transcriptional pausing and cap formation on three Drosophila heat shock genes. Proc. Natl. Acad. Sci. 90: 7923-7927.

Ratnasabapathy, R., M. Sheldon, L. Johal, and N. Hernandez 1990. The HIV-1 long terminal repeat contains an unusual element that induces the synthesis of short RNA from various mRNA and snRNA promoters. Genes \& Dev. 4: 20612074.

Roberts, J.W. 1993. RNA and protein elements of E. coli and lambda transcription antitermination complexes. Cell 72: 653-655.

Rougvie, A.E. and J.T. Lis. 1988. The RNA polymerase II at the $5^{\prime}$ end of the uninduced hsp70 gene of the D. melanogaster is transcriptionally engaged. Cell 54: 795-804.

Sambrook, J., E.F. Fritsch, and T. Maniatis. 1989. Molecular cloning: A laboratory manual, 2nd ed. Cold Spring Harbor Laboratory Press, Cold Spring Harbor, New York.

Sadowski, I., J. Ma, S. Triezenberg, and M. Ptashne. 1988. GAL4-VP16 is an unusually potent transcriptional activator. Nature 335: 563-564.

Sheldon, M., R. Ratnasabapathy, and N. Hernandez. 1993. Characterization of the inducer of short transcripts, a human immunodeficiency virus type 1 transcriptional element that activates the synthesis of short RNAs. Mol. Cell. Biol. 13: $1251-1263$.

Smale, S.T. 1994. Core promoter architecture for eukaryotic protein coding genes. In Transcription: Mechanisms and regulation (ed. R.C. Conaway and J.W. Conaway), pp. 63-81. Raven Press, New York.

Smale, S. and D. Baltimore. 1989. The initiator as a transcriptional control element. Cell 57: 103-113.

Smale, S., M.C. Schmidt, A.J. Berk, and D. Baltimore 1990. Transcriptional activation by $\mathrm{Spl}$ as directed through TATA or initiator: Specific requirement for mammalian transcription factor IID. Proc. Natl. Acad. Sci. 87: 4509-4513.

Southgate, C.D. and M.R. Green. 1991. The HIV-1 Tat protein activates transcription from an upstream DNA-binding site: Implications for Tat function. Genes \& Dev. 5: 2496-2507.

Spencer, C.A. and M. Groudine. 1990. Transcription elongation and eukaryotic gene regulation. Oncogene 5: 777-785.

Spencer, C.A., R.C. LeStrange, U. Novak, W.S. Hayward, and M. Groudine. 1990. The block to transcription elongation is promoter dependent in normal and Burkitt's lymphoma c-myc alleles. Genes \& Dev. 4: 75-88.

Strobl, L.J. and D. Eick. 1992. Hold back of RNA polymerase II at the transcription start mediates down-regulation of c-myc in vivo. $E M B O ~ / .11: 3307-3314$.

Thalmeier, K., H. Synovzik, R. Mertz, E.L. Winnacker, and M. Lipp. 1989. Nuclear factor E2F mediates basic transcription and trans-activation by Ela of the human c-myc promoter. Genes \& Dev. 3: 527-536.

Wang, W. and J.D. Gralla. 1991. Differential ability of proximal and remote element pairs to cooperate in activating RNA 
Krumm et al.

polymerase II transcription. Mol. Cell. Biol. 11: 4561-4571.

Wang, W., J.D. Gralla, and M. Carey. 1992. The acidic activator Gal4-AH can stimulate polymerase II transcription by promoting assembly of a closed complex requiring TFIID and TFIIA. Genes \& Dev. 6: 1716-1726.

Weeks, J.R., S.E. Hardin, J. Shen, J.M. Lee, and A. Greenleaf. 1993. Locus-specific variation in phosphorylation state of RNA polymerase II in vivo: Correlations with gene activity and transcript processing. Genes \& Dev. 7: 2329-2344.

Weisbrod, S., M. Groudine, and H. Weintraub. 1980. Interaction of HMG 14 and 17 with actively transcribed genes. Cell 19: 289-301.

White, J., C. Brou, J. Wu, Y. Lutz, V. Moncollin, and P. Chambon. 1992. The acidic transcriptional activator GAL-VP16 acts on preformed template-committed complexes. EMBO $I$. 11: $2229-2240$.

Workman, I.L., I.C.A. Taylor, and R.E. Kingston. 1991. Activation domains of stably bound Gal4 derivatives alleviate repression of promoters by nucleosomes. Cell 64: 533-544.

Xiao, H., A. Pearson, B. Coulombe, R. Truant, S. Zhang, J.L. Regier, S.J. Triezenberg, D. Reinberg, O. Flores, J. Ingles, and J. Greenblatt. 1994. Binding of basal transcription factor TFIIH to the acidic activation domains of VP16 and p53. Mol. Cell. Biol. 14: 7013-7024.

Yankulov, K., J. Blau, T. Purton, S. Roberts, and D.L. Bentley. 1994. Transcriptional elongation by RNA polymerase II is stimulated by transactivators. Cell 77: 749-759. 


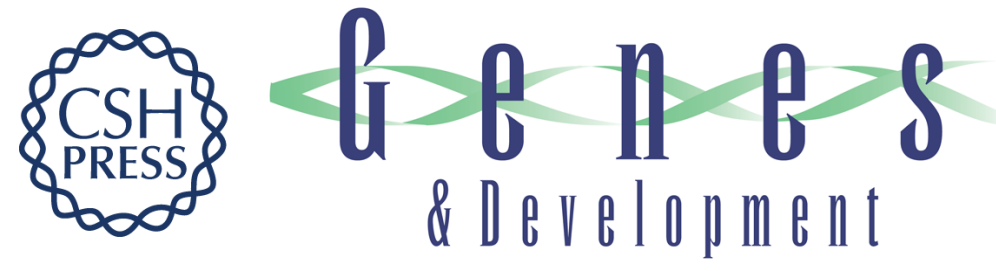

\section{Promoter-proximal pausing of RNA polymerase II defines a general rate-limiting step after transcription initiation.}

A Krumm, L B Hickey and M Groudine

Genes Dev. 1995, 9:

Access the most recent version at doi:10.1101/gad.9.5.559

References This article cites 65 articles, 38 of which can be accessed free at:

http://genesdev.cshlp.org/content/9/5/559.full.html\#ref-list-1

License

Email Alerting

Service

Receive free email alerts when new articles cite this article - sign up in the box at the top right corner of the article or click here.

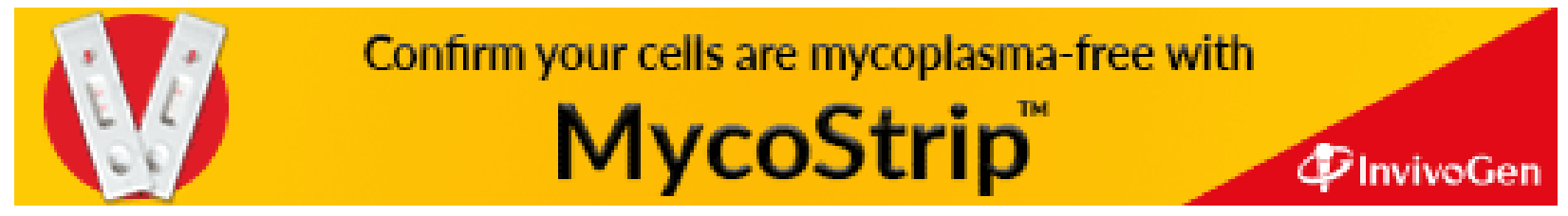

